\title{
Relation between place of residence and postpartum depression
}

\author{
Simone N. Vigod MD MSc, Lesley A. Tarasoff MA, Barbara Bryja RM, Cindy-Lee Dennis PhD, \\ Mark H. Yudin MD MSc, Lori E. Ross PhD
}

See also the editorial by Patrick on page 1115 and at www.cmaj.ca/lookup/doi/10.1503/cmaj.131248

\begin{abstract}
Background: The relation between place of residence and risk of postpartum depression is uncertain. We evaluated the relation between place of residence and risk of postpartum depression in a population-based sample of Canadian women.
\end{abstract}

Methods: Female postpartum respondents to the 2006 Canadian Maternity Experiences Survey $(n=6126)$ were classified as living in rural (< 1000 inhabitants or population density $<400 / \mathrm{km}^{2}$ ), semirural (nonrural but $<30000$ inhabitants), semiurban (30 000-499 999 inhabitants) or urban ( $\geq 500000$ inhabitants) areas. We further subdivided women living in rural areas based on the social and occupational connectivity of their community to larger urban centres. We compared the prevalence of postpartum depression (score of $\geq 13$ on the Edinburgh Postnatal Depression Scale) across these groups and adjusted for the effect of known risk factors for postpartum depression.
Results: The prevalence of postpartum depression was higher among women living in urban areas than among those living in rural, semirural or semiurban areas. The difference between semiurban and urban areas could not be fully explained by other measured risk factors for postpartum depression (adjusted odds ratio $0.60,95 \%$ confidence interval $0.42-0.84$ ). In rural areas, there was a nonsignificant gradient of risk: women with less connection to larger urban centres were at greater risk of postpartum depression than women in areas with greater connection.

Interpretation: There are systematic differences in the distribution of risk factors for postpartum depression across geographic areas, resulting in an increased risk of depression among women living in large urban areas. Prevention programs directed at modifiable risk factors (e.g., social support) could specifically target women living in these areas to reduce the rates of postpartum depression.
$\mathrm{P}$ ostpartum depression is an internationally recognized health concern for women and their families. Depression during the perinatal period is associated with serious negative consequences for both mother and baby, particularly if the depression is untreated. ${ }^{1}$ Outcomes among women include impaired functioning, poor quality of life and death. ${ }^{2}$ Outcomes for infants include developmental delay, poor growth, malnutrition and illness. ${ }^{3-5}$ Numerous risk factors for postpartum depression have been identified; low levels of social support and history of depression are among the variables most consistently associated with postpartum depression..$^{6-8}$ However, previous reports are inconsistent as to whether geographical size or location is associated with the risk of postpartum depression. ${ }^{9}$ In Canada, about $30 \%$ of the population lives in rural or remote areas, a large proportion live in several large urban areas, and the remainder live in smaller urban settings. ${ }^{10}$ To design appropriate supports and services for the prevention and treatment of postpartum depression among Canadian women, it is important to identify and target geographical variation in the risk of postpartum depression.

Our primary objective was to compare the risk of postpartum depression among Canadian women living in rural and urban areas. Our secondary objective was to identify factors that could explain any associations between place of residence and risk of postpartum depression. We used multiple definitions of rural and urban locations to more accurately reflect differences between communities and to account for the level of social and occupational connectivity of smaller areas to more urban areas.

\section{Methods}

\section{Study design}

We used a population-based Canadian survey of women who had recently given birth (the Mater-
Competing interests: Simone Vigod has received a consulting fee from MultiDimensional Health Care for the development of continuing health care activities related to perinatal mental health. No competing interests declared by the other authors.

This article has been peer reviewed.

Correspondence to: Simone N. Vigod, simone.vigod@wchospital.ca

CMAJ 2013. DOI:10.1503 /cmaj.122028 
nity Experiences Survey ${ }^{11}$ ); this survey was performed by the Public Health Agency of Canada and the Canadian Perinatal Surveillance System. This national cross-sectional survey collected information on key perinatal health indicators from recent mothers in all provinces and territories using the 2006 Canadian Census sampling frame. Sampling was stratified by province or territory to ensure adequate sample size in specific groups, and certain vulnerable groups and low population-density regions were oversampled to ensure adequate sample size for the analysis of those groups. A simple random sample without replacement was drawn from each stratum. ${ }^{11}$ Mothers living on First Nations reserves and in collective dwellings were excluded from the sampling frame. The response rate was high $(78 \%)$, and the responses were collected (primarily by telephone) by use of computer-assisted interviews with women who had a singleton birth between Feb. 15 and May 15, 2006, in the provinces and between Nov. 1, 2005, and Feb. 1, 2006, in the territories. The included mothers were all over the age of 15 years and were living with their child at the time of the interview. The response rate was $78 \%$ (6421/8244 women contacted), representing about 76500 Canadian women (after applying survey weights).

For the present study, Health Canada's Science Advisory Board and Research Ethics Board and the Federal Privacy Commissioner reviewed the research protocol, and approval was received from Statistics Canada's Policy Committee before implementation. We accessed the data through an application process to the Social Sciences and Humanities Council of Canada. Our study was also approved by the Research Ethics Board at the Centre for Addiction and Mental Health in Toronto, Ontario.

\section{Exposure definitions}

Our definitions of rural and urban areas were based on a Canadian framework for defining rurality advanced by Statistics Canada. This framework uses strategies that capitalize on potential differences between communities, not only in terms of population size, but also in terms of social and occupational connectivity with larger centres..$^{10,12}$

We used 3 methods to define rural and urban areas: population size and density; population size of an area's urban core (areas with $<10000$ people living in an urban core were considered rural and small town); and the proportion of individuals in rural areas who commute to larger urban centres (classified into strong, moderate and weak metropolitan-influenced zones).

We defined rural populations as those outside settlements of 1000 or more people or outside areas with a population density of 400 or more inhabitants per square kilometre. We further classified remaining women as living in semirural (population $<30000$ ), semiurban (population 30 000-499 999) or urban (population $\geq 500000)$ areas.

In our secondary analyses, we used additional definitions from Statistics Canada that better reflect the degree of connectivity of small towns to larger urban settings in a way that is not captured by population size alone. In this definition, individuals living within census metropolitan areas and census agglomerations are considered to be living in a "larger urban centre." In Canada, a census metropolitan area has a total population of 100000 or more people, with 50000 or more in the urban core, and a census agglomeration has an urban core of 10000 or more people. Both include neighbouring towns and municipalities where $50 \%$ or more of the workforce commutes to the urban core. ${ }^{13,14}$ Individuals living outside census metropolitan areas and census agglomerations are classified as living in "rural and small town" areas.

To separate the women with the most potential for social isolation from those with less potential for isolation, we further divided women living in rural and small town areas by "metropolitan-influenced zone." These zones indicate the percentage of residents who commute to larger urban centres. The zones are designated as strong ( $\geq 30 \%$ of residents commute to an urban core), moderate $(5 \%-29 \%)$, weak $(>0 \%$, but $<5 \%)$ or no $(0 \%)$ metropolitan influence. ${ }^{10,15}$

\section{Outcome measures}

Our primary outcome was postpartum depression, as measured by use of the 10-item Edinburgh Postnatal Depression Scale,${ }^{16}$ which was administered to all survey respondents. This is the most widely used screening questionnaire for postpartum depression, and it has good discriminant validity. The risk of postpartum depression (as confirmed by clinical diagnosis) is increased more than 10 times among women who score $\geq 13$ points. ${ }^{17}$

\section{Covariates}

The Maternity Experiences Survey contains information about sociodemographic and medical characteristics and health service use. The variables of interest were age, parity, marital status, socioeconomic status, education status, country of birth (Canadian born v. non-Canadian born), recent immigration (within $5 \mathrm{yr}$ ), distance travelled to give birth, history of depression, life stressors, abuse, social support during pregnancy and the postpartum period, substance and alcohol use, 
type of antenatal care provider, and complications during pregnancy, delivery and the perinatal period (e.g., cesarean section, preterm birth, birth weight, stay in the neonatal intensive care unit).

\section{Statistical analysis}

The data were analyzed using SAS version 9.3 at the Toronto Region Statistics Canada Research Data Centre. We used population weights sup- plied by Statistics Canada to weight all estimates to represent the population at the time of the survey. To account for the complex cluster-sample design of the survey, we used a weighted bootstrapping resampling procedure to calculate the coefficients of variation for the estimates. We did not report estimates for which the coefficients of variation were greater than $33.3 \%$, because this indicates a high likelihood of bias in the esti-

Table 1: Baseline characteristics of 6126 new mothers who completed the Maternity Experiences Survey, by location

\begin{tabular}{|c|c|c|c|c|}
\hline \multirow[b]{2}{*}{ Characteristic } & \multicolumn{4}{|c|}{ Location; weighted \% $(95 \% \mathrm{Cl})$ * } \\
\hline & $\begin{array}{c}\text { Rural } \\
n=1362\end{array}$ & $\begin{array}{c}\text { Semirural } \\
n=1225\end{array}$ & $\begin{array}{l}\text { Semiurban } \\
n=2187\end{array}$ & $\begin{array}{l}\text { Urban } \\
n=1352\end{array}$ \\
\hline Maternal age, yr, mean $(95 \% \mathrm{Cl})$ & $29.7(29.5-30.0)$ & $29.5(29.2-29.8)$ & $29.5(29.3-29.7)$ & $31.1(31.0-31.3)$ \\
\hline Parity, primiparous & $39.6(37.0-42.2)$ & $40.8(37.9-43.6)$ & $49.4(46.9-51.9)$ & $47.0(45.5-48.6)$ \\
\hline Marital status, married or common-law & $92.7(91.2-94.2)$ & $91.0(89.4-92.6)$ & $88.6(87.0-90.3)$ & $93.2(92.2-94.2)$ \\
\hline Born in Canada & $89.0(87.0-91.0)$ & $88.1(86.0-90.2)$ & $87.2(85.3-89.2)$ & $61.9(59.9-63.9)$ \\
\hline \multicolumn{5}{|l|}{ Household incomet } \\
\hline Lowest & $10.5(8.85-12.2)$ & $9.9(8.12-11.6)$ & $12.0(10.1-13.8)$ & $11.2(9.82-12.5)$ \\
\hline Lower-middle & $23.9(21.4-26.3)$ & $18.8(16.4-21.3)$ & $21.5(19.2-23.8)$ & $20.5(18.7-22.3)$ \\
\hline Upper-middle & $37.6(34.7-40.5)$ & $36.9(33.9-40.0)$ & $36.6(33.9-39.3)$ & $30.9(28.9-32.9)$ \\
\hline Highest & $28.0(25.2-30.8)$ & $34.4(31.4-37.4)$ & $29.9(27.3-32.5)$ & $37.4(35.5-39.4)$ \\
\hline \multicolumn{5}{|l|}{ Education level } \\
\hline Less than high school & $8.82(7.3-10.4)$ & $9.87(8.10-11.6)$ & $7.79(6.42-9.16)$ & $5.94(4.98-6.90)$ \\
\hline High school & $15.5(13.4-17.6)$ & $16.2(13.9-18.4)$ & $15.1(13.0-17.1)$ & $10.8(9.53-12.0)$ \\
\hline Some postsecondary & $19.0(16.7-21.2)$ & $16.2(14.0-18.3)$ & $16.9(14.9-19.0)$ & $13.9(12.5-15.4)$ \\
\hline Postsecondary & $56.8(53.8-59.7)$ & $57.8(54.8-60.8)$ & $60.2(57.5-62.9)$ & $69.4(67.5-71.2)$ \\
\hline History of depression & $16.4(14.1-18.6)$ & $16.4(14.2-18.6)$ & $18.7(16.6-20.9)$ & $13.5(12.0-14.9)$ \\
\hline Maternal health, excellent or very good & $73.3(70.7-75.8)$ & $73.1(70.4-74.8)$ & $75.1(72.7-77.5)$ & $70.7(68.8-72.6)$ \\
\hline \multicolumn{5}{|l|}{ Stress } \\
\hline $\begin{array}{l}\text { No. of life stressors in last } 2 \mathrm{yr} \text {, } \\
\text { mean }(95 \% \mathrm{Cl})\end{array}$ & $1.25(1.17-1.34)$ & $1.37(1.27-1.46)$ & $1.38(1.30-1.47)$ & $1.19(1.13-1.25)$ \\
\hline Abuse in last $2 \mathrm{yr}$ & $9.82(8.21-11.4)$ & $12.6(10.6-14.5)$ & $13.1(11.3-14.9)$ & $9.94(8.79-11.1)$ \\
\hline Labour and delivery complications & $14.3(12.2-16.4)$ & $14.4(12.3-16.5)$ & $14.6(12.7-16.6)$ & $14.9(13.4-16.3)$ \\
\hline Preterm birth & $6.06(4.62-7.50)$ & $6.49(4.90-8.08)$ & $6.67(2.30-8.04)$ & $6.15(5.13-7.18)$ \\
\hline Infant in NICU & $10.8(8.98-12.5)$ & $11.0(9.06-12.8)$ & $14.8(12.8-16.8)$ & $13.0(11.6-14.4)$ \\
\hline \multicolumn{5}{|l|}{ Social support } \\
\hline \multicolumn{5}{|l|}{ Pregnancy } \\
\hline None or a little of the time & $4.52(3.28-5.76)$ & $4.05(2.82-5.28)$ & $3.52(2.54-4.51)$ & $6.21(5.18-7.24)$ \\
\hline Some of the time & $6.65(5.21-8.10)$ & $6.87(5.29-8.46)$ & $6.25(4.91-7.59)$ & $9.21(8.00-10.4)$ \\
\hline Most of the time & $27.9(25.2-30.6)$ & $30.0(27.1-32.9)$ & $27.4(24.9-29.9)$ & $31.4(29.5-33.4)$ \\
\hline All of the time & $60.9(58.0-63.8)$ & $59.1(56.0-62.1)$ & $62.8(60.1-65.5)$ & $53.1(51.1-55.2)$ \\
\hline \multicolumn{5}{|l|}{ Postpartum } \\
\hline None or a little of the time & $4.51(3.32-5.70)$ & $5.34(3.89-6.79)$ & $4.82(3.67-5.96)$ & $6.53(5.50-7.55)$ \\
\hline Some of the time & $9.48(7.74-11.2)$ & $8.51(6.84-10.2)$ & $8.42(6.82-10.0)$ & $12.2(10.8-13.6)$ \\
\hline Most of the time & $31.8(29.0-34.5)$ & $33.4(30.5-36.3)$ & $31.2(28.6-33.9)$ & $34.1(32.1-36.1)$ \\
\hline All of the time & $54.3(51.4-57.1)$ & $52.8(49.7-55.9)$ & $55.5(52.8-58.3)$ & $47.2(45.1-49.3)$ \\
\hline
\end{tabular}

Note: $\mathrm{Cl}=$ confidence interval, $\mathrm{NICU}=$ neonatal intensive care unit.

*Unless otherwise stated.

tHousehold income is reported by quartile. 
mate. ${ }^{18}$ We calculated the weighted prevalence of postpartum depression (score $\geq 13$ on the Edinburgh Postnatal Depression Scale) for the entire population and subsequently for the exposure groups using each definition of rurality. We described and compared the prevalence of postpartum depression among women living in rural, semirural, semiurban and urban areas. We then generated adjusted odds ratios (ORs) and 95\% confidence intervals (CIs) using the urban group as the referent category. We adjusted the multivariable models for known risk factors of postpartum depression (history of depression, life stressors, interpersonal abuse, social support and maternal self-reported health), ${ }^{19}$ as well as for covariates for which clinically significant differences were observed between groups for potential prognostic variables.

In our secondary analysis, we compared the prevalence of postpartum depression among women living in rural and small town areas to the prevalence among women living in large urban centres. Among women who lived in rural and small town areas, we compared the prevalence of postpartum depression between women living in areas designated as having strong, moderate, weak and no metropolitan influence.

\section{Results}

The weighted prevalence of postpartum depression in the overall sample was $7.47 \%$ (95\% CI
$6.76 \%-8.17 \%$ ), and the weighted mean score on the Edinburgh Postnatal Depression Scale was 5.27 (95\% CI 5.16-5.39). Descriptive characteristics are shown in Table 1. Compared with women in the urban group, women in the other groups were slightly younger, more likely to be born in Canada and less likely to receive their obstetrical care from an obstetrician (v. family practitioner) (data not shown). Compared with women who lived in urban areas, women in the other groups were less likely to have postsecondary education and to be in the highest income quintile. Over $50 \%$ of women in the rural group and $44 \%$ of women in the semirural group indicated that they had to travel outside of their community to give birth (v. $11 \%$ of semiurban and $15 \%$ of urban women). Women in urban areas reported lower rates of depression history and fewer stressful life events compared with women in the other groups. However, a smaller proportion of women in urban areas reported that they were in excellent or very good health, and they were less likely to report adequate social support during pregnancy and the postpartum period.

The prevalence of postpartum depression varied depending on urban, semiurban, semirural and rural area, as did the mean score on the Edinburgh Postnatal Depression Scale. Women in the urban group were at higher risk of postpartum depression than women in the other groups (Table 2). When we compared women in the

\begin{tabular}{|c|c|c|}
\hline Characteristic & $\begin{array}{c}\text { EPDS } \geq 13,+ \\
\text { weighted } \%(95 \% \mathrm{Cl})\end{array}$ & $\begin{array}{c}\text { EPDS score, } \\
\text { weighted mean }(95 \% \mathrm{Cl})\end{array}$ \\
\hline \multicolumn{3}{|l|}{ Location¥ } \\
\hline Rural, $n=1362$ & $6.07(4.66-7.48)$ & $4.94(4.68-5.20)$ \\
\hline Semirural, $n=1225$ & $6.96(5.39-8.53)$ & $5.05(4.78-5.33)$ \\
\hline Semiurban, $n=2187$ & $5.31(4.01-5.61)$ & $5.00(4.77-5.24)$ \\
\hline Urban, $n=1352$ & $9.16(7.50-10.40)$ & $5.61(5.41-5.81)$ \\
\hline \multicolumn{3}{|c|}{ Census metropolitan and census agglomeration areas } \\
\hline Rural and small town, $n=1248$ & $6.98(5.48-8.48)$ & $5.03(4.77-5.30)$ \\
\hline Large urban centre $n=4878$ & $7.56(6.75-8.37)$ & $5.33(5.19-5.46)$ \\
\hline \multicolumn{3}{|c|}{ Rural and small-town areas, by metropolitan influence } \\
\hline Strong, $n=316$ & $5.50(2.94-8.06)$ & $5.18(4.73-5.64)$ \\
\hline Moderate, $n=444$ & $7.05(4.53-9.58)$ & $4.91(4.47-5.35)$ \\
\hline Weak, $n=440$ & $8.31(5.60-11.00)$ & $5.14(4.68-5.60)$ \\
\hline None, $n=48$ & NR & $4.06(2.78-5.33)$ \\
\hline \multicolumn{3}{|c|}{$\begin{array}{l}\text { Note: } \mathrm{Cl}=\text { confidence interval, EPDS = Edinburgh Postnatal Depression Scale, } \mathrm{NR}=\text { not reportable. } \\
{ }^{*} \text { Differences between groups were evaluated using } \chi^{2} \text { tests for categorical variables and independent } t \text { test or analysis of } \\
\text { variance (ANOVA) for continuous variables. } \\
\text { tEPDS } \geq 13 \text { represents likelihood that a woman has postpartum depression. } \\
\neq p<0.05 \text { for differences between groups for both EPDS } \geq 13 \text { and EPDS mean score. }\end{array}$} \\
\hline
\end{tabular}


rural and small town group with those living in larger urban centres, women in the latter group had nonsignificantly higher prevalence of postpartum depression and mean score on the Edinburgh Postnatal Depression Scale (Table 2).

There were no statistically significant differences in the prevalence of postpartum depression among women living in rural areas when we examined prevalence by level of influence from a metropolitan zone. There was a nonsignificant gradient in which the prevalence was highest among women in areas with weak metropolitan influence. There was a slightly lower prevalence among women in moderate zones, and prevalence was lowest among women in strong metropolitan-influenced zones $(5.50 \%$, 95\% CI 2.94-8.06). The mean scores on the Edinburgh Postnatal Depression Scale followed similar trends (Table 2).

After adjusting for known predictors of postpartum depression and possible prognostic variables (parity, country of origin, household income) for which we found clinically significant differences, we were able to explain the higher risk among urban women, but not for the lower-risk women in the semiurban group, who remained at significantly lower risk of postpartum depression than women in the urban group (OR 0.60, 95\% CI 0.42-0.84) (Table 3).

\section{Interpretation}

We found that Canadian women who lived in large urban areas (i.e., population $>500000$ inhabitants) were at higher risk of postpartum depression than women living in other areas. The risk factors for postpartum depression (including history of depression, social support and immigration status) that were unequally distributed across geographic regions accounted for most of the variance in the rates of postpartum depression. Combining women in large urban areas with those who lived outside rural and small town areas obscured differences in the rates of postpartum depression across geographic regions, suggesting that more sophisticated definitions of urbanicity are required for research in this area.

The overall prevalence of postpartum depression of $7.47 \%$ in this study is lower than the traditionally reported rates in developed countries (about 13\%), ${ }^{8}$ but this rate is consistent with the prevalence reported in other population-based studies conducted in the latter part of the first postpartum year. ${ }^{8}$ The prevalence rate that we observed among women in rural areas was substantially lower than the combined prevalence rate of postpartum depression of $21.5 \%$ (95\% CI
$10.9 \%-38.0 \%$ ) among rural women observed in our previous meta-analysis on this topic. ${ }^{10}$ However, most of the studies included in the systematic review involved selected populations with many risk factors for postpartum depression (e.g., high prevalence of single mothers, low socioeconomic status), which would potentially inflate the prevalence estimates. Only 3 of the studies in the systematic review included comparison groups of women living in nonrural areas; the results of these studies were more con-

Table 3: Multivariable model for the relationship between population area size and postpartum depression (EPDS $\geq 13$ )

\begin{tabular}{|c|c|}
\hline Main exposure variable & Odds ratio $(95 \% \mathrm{Cl})$ \\
\hline & Unadjusted \\
\hline \multicolumn{2}{|l|}{ Population area size } \\
\hline Urban & Ref \\
\hline Semiurban & $0.56 \quad(0.41-0.75)$ \\
\hline Semirural & $0.74 \quad(0.56-0.99)$ \\
\hline \multirow[t]{2}{*}{ Rural } & $0.64 \quad(0.48-0.85)$ \\
\hline & Adjusted* \\
\hline \multicolumn{2}{|l|}{ Population area size } \\
\hline Urban & Ref \\
\hline Semiurban & $0.60 \quad(0.42-0.84)$ \\
\hline Semirural & $0.90 \quad(0.65-1.24)$ \\
\hline Rural & $0.80 \quad(0.57-1.11)$ \\
\hline Parity, primiparous & $0.82 \quad(0.64-1.05)$ \\
\hline $\begin{array}{l}\text { Country of origin (Canadian-born } \\
\text { v. non-Canadian-born) }\end{array}$ & $0.51 \quad(0.39-0.67)$ \\
\hline \multicolumn{2}{|l|}{ Household income } \\
\hline Low & Ref \\
\hline Low-middle & $0.88 \quad(0.57-1.20)$ \\
\hline Middle-high & $0.82 \quad(0.60-1.29)$ \\
\hline High & $0.80 \quad(0.54-1.17)$ \\
\hline $\begin{array}{l}\text { History of depression (v. no } \\
\text { history) }\end{array}$ & $2.11 \quad(1.60-2.79)$ \\
\hline Life stressors & $1.29 \quad(1.20-1.38)$ \\
\hline Interpersonal abuse & $1.46 \quad(1.06-2.00)$ \\
\hline \multicolumn{2}{|l|}{ Maternal health } \\
\hline Good/fair/poor & Ref \\
\hline Excellent/very good & $0.40 \quad(0.31-0.51)$ \\
\hline \multicolumn{2}{|l|}{ Postpartum social support } \\
\hline Low & Ref \\
\hline Low-middle & $0.67 \quad(0.45-1.00)$ \\
\hline Middle-high & $0.36 \quad(0.25-0.52)$ \\
\hline High & $0.15 \quad(0.10-0.23)$ \\
\hline
\end{tabular}

Note: $\mathrm{Cl}=$ confidence interval, EPDS = Edinburgh Postnatal Depression Scale, ref $=$ reference. *All variables were adjusted for all covariates in the model. We included variables that are known predictors of postpartum depression (history of depression, life stressors in past $2 \mathrm{yr}$, interpersonal abuse in last $2 \mathrm{yr}$, social support, maternal self-reported health) or those for which there were major differences between groups for possible prognostic variables (parity, country of origin, household income). Hosmer-Lemeshow for goodness of fit of the multivariable model $X^{2}=8.43, p=0.4$. All variance inflation factors $<1.30$. 
sistent with the results of the current study. Two studies found no significant differences in the risk of depression at 6-8 weeks postpartum. ${ }^{20,21}$ In the third study, Australian women from nonmetropolitan areas $(n=213)$ had significantly lower odds (OR $0.54,95 \%$ CI $0.33-0.90$ ) of depression at 8-9 months postpartum than did women living in metropolitan areas $(n=535){ }^{22}$ These results are not surprising, because outcomes can change depending on the definition of the rural exposure group.

\section{Limitations}

As with most population-based surveys, the potential limitations include the self-reported nature of the data, as well as the potential for a sampling bias of healthy respondents (with telephone access). The sampling frame excluded women living on First Nations Reserves or in group dwellings. Although the psychometric properties and predictive validity of the Edinburgh Postnatal Depression Scale as a measure of postpartum depression have been well-established, diagnostic confirmation for postpartum depression was not available.

Because of the cross-sectional nature of the data, we can only hypothesize about causal pathways to explain the observed variability in postpartum depression across regions of different population size.

We were limited to the variables collected in the survey. Certain elements important to social support and social capital such as marital discord and access to supportive resources may not have been captured by the 4-item social support scale. This may explain why we were unable to account for all of the observed variability in the risk of postpartum depression across geographic regions.

\section{Conclusion}

Our study helps to clarify the relation between place of residence and risk of postpartum depression in Canada. Our findings suggest that women in urban areas with a large population were at increased risk of postpartum depression compared with women in other regions. Geographical differences in the distribution of important risk factors for postpartum depression, such as immigration status, interpersonal violence, selfperceived health and social support, account for much of this variance.

Supports and services targeted toward increasing connections for isolated women in large urban centres may need to be increased in Canada. Considering the substantial negative effect of postpartum depression, such interventions could have broad-reaching social and public health impact. Other countries might also benefit from studying the levels of perceived social support across regions, particularly in cases where geographical variation in the rates of postpartum depression is observed. Further, our results show that careful consideration of the definitions of rurality and urbanicity is essential because of the way the results depend on how geographical exposure is defined.

\section{References}

1. Brand SR, Brennan PA. Impact of antenatal and postpartum maternal mental illness: How are the children? Clin Obstet Gynecol 2009;52:441-55

2. Brockington I. Postpartum psychiatric disorders. Lancet 2004; 363:303-10.

3. Patel V, DeSouza N, Rodrigues M. Postnatal depression and infant growth and development in low income countries: a cohort study from Goa, India. Arch Dis Child 2003;88:34-7.

4. Austin MP, Hadzi-Pavlovic D, Leader L, et al. Maternal trait anxiety, depression and life event stress in pregnancy: relationships with infant temperament. Early Hum Dev 2005;81:183-90.

5. Berle JØ, Mykletun A, Daltveit AK, et al. Neonatal outcomes in offspring of women with anxiety and depression during pregnancy. A linkage study from The Nord-Trondelag Health Study (HUNT) and Medical Birth Registry of Norway. Arch Womens Ment Health 2005;8:181-9.

6. Robertson E, Grace S, Wallington T, et al. Antenatal risk factors for postpartum depression: a synthesis of recent literature. Gen Hosp Psychiatry 2004;26:289-95.

7. Beck CT. Predictors of postpartum depression: an update. Nurs Res 2001;50:275-85.

8. O'Hara MW, Swain AM. Rates and risk for postpartum depression — a meta-analysis. Int Rev Psychiatry 1996;8:37-54.

9. Villegas L, McKay K, Dennis C-L, et al. Postpartum depression among rural women from developed and developing countries: a systematic review. J Rural Health 2011;27:278-88.

10. du Plessis V, Beshiri R, Bollman RD, et al. Definitions of rural. Rural and small town Canada analysis bulletin. Ottawa (ON): Statistics Canada; 2001. Cat. no. 21-006-XIE. Available: www .statcan.gc.ca/pub/21-006-x/21-006-x2001003-eng.pdf (accessed 2013 July 19).

11. What mothers say: the Canadian maternity experiences survey. Ottawa (ON): Public Health Agency of Canada; 2009. Available: www.phac-aspc.gc.ca/rhs-ssg/pdf/survey-eng.pdf (accessed 2013 July 19).

12. du Plessis V, Beshiri R, Bollman RD, et al. Definitions of rural. Agriculture and rural working group paper. Ottawa (ON): Statistics Canada; 2002. Cat. no. 21-601-M. 61. Available: www.geo .mtu.edu/ asmayer/rural_sustain/intro/further_reading/definition _rural_canada.pdf (accessed 2013 July 19).

13. Bollman RD, Prud'homme M. Trends in the prices of rurality. Ottawa (ON): Statistics Canada; 2006. Cat. no. 21-006-X. Available: http://publications.gc.ca/collection/statcan/21-006-X/21006-XIE2005007.pdf (accessed 2013 July 19).

14. Spencer H, Alasia A, Bollman RD. Rural commuting: its relevance to rural and urban labour markets. Ottawa (ON): Statistics Canada; 2008. Cat. no 21-006-X. Available: www.statcan.gc.ca /pub/21-006-x/21-006-x2007006-eng.htm (accessed 2013 July 19).

15. McNiven C, Puderer H, Janes D. Census metropolitian area and census agglomeration influenced zones (MIZ): a description of the methodology. Ottawa (ON): Statistics Canada; 2000. Cat. no. 92F0138M. Available: www5.statcan.gc.ca/bsolc/olc-cel/olc-cel ?lang=eng\&catno=92F0138M2000002 (accessed 2013 July 19).

16. Cox JL, Holden JM, Sagovsky R. Detection of postnatal depression: development of the 10-item Edinburgh Postnatal Depression Scale. Br J Psychiatry 1987;150:782-6.

17. Eberhard-Gran M, Eskild A, Tambs K, et al. Review of validation studies of the Edinburgh Postnatal Depression Scale. Acta Psychiatr Scand 2001;104:243-9.

18. Estimation of the variance using bootstrap weights: user's guide for the BOOTVAREV30.SPS program (Version 3.0). Ottawa (ON): Statistics Canada; 2002.

19. Dennis C.-L., Heaman M, Vigod S. Epidemiology of postpartum depressive symptoms among Canadian women: regional and national results from a cross-sectional survey. Can J Psychiatry 2012;57:537-46.

20. Johnstone SJ, Boyce PM, Hickey AR, et al. Obstetric risk factors for postnatal depression in urban and rural community samples. Aust N Z J Psychiatry 2001;35:69-74. 
21. Bilszta JL, Gu YZ, Meyer D, et al. A geographic comparison of the prevalence and risk factors for postnatal depression in an Australian population. Aust N Z J Public Health 2008;32:424-30.

22. Astbury J, Brown S, Lumley J, et al. Birth events, birth experiences and social differences in postnatal depression. Aust J Public Health 1994;18:176-84.

Affiliations: Women's Mental Health Program (Vigod), Women's College Hospital; Department of Psychiatry (Vigod, Dennis, Ross), University of Toronto; Women's College Research Institute (Vigod, Dennis, Ross); Social and Epidemiological Research Department (Tarasoff, Ross), Centre for Addiction and Mental Health; Dalla Lana School of Public Health (Tarasoff, Ross), University of Toronto, Toronto, Ont.; Midwives Grey Bruce (Bryja), Owen Sound, Ont.; Lawrence S. Bloomberg Faculty of Nursing (Dennis), University of Toronto, Toronto, Ont.; Department of Obstetrics and Gynecology (Yudin), St. Michael's Hospital; Department of Obstetrics and Gynecology (Yudin), University of Toronto, Toronto, Ont.

Contributors: Simone Vigod, Lori Ross and Cindy-Lee Dennis contributed to the conception of the study, and all of the authors contributed to the study's design. Simone Vigod and Lori Ross led the statistical analysis. Lesley Tarasoff, Simone Vigod and Lori Ross prepared the first draft of the manuscript. All of the authors critically revised the manuscript for important intellectual content and approved the final version submitted for publication.

Funding: Simone Vigod is supported by the Shirley Brown Clinician Scientist Award (Women's College Hospital, Centre for Addiction and Mental Health, and the University of Toronto) and by the Departments of Psychiatry at the Women's College Hospital and the University of Toronto. Lori Ross is supported as a New Investigator by the Canadian Institutes of Health Research and Ontario Women's Health Council (award no. NOW-84656). Support to the Centre for Addiction and Mental Health for salary of scientists and infrastructure has been provided by the Ontario Ministry of Health and Long-Term Care. No operating grant funding was used to support this work. The views expressed here do not necessarily reflect those of the Women's College Hospital, the Centre for Addiction and Mental Health, or the Ontario Ministry of Health and Long-Term Care.

\section{GET THE CREDIT YOU DESERVE}

\begin{abstract}
New online accredited CME courses just released
\end{abstract}

Free for CMA members

Register at:

cma.ca/
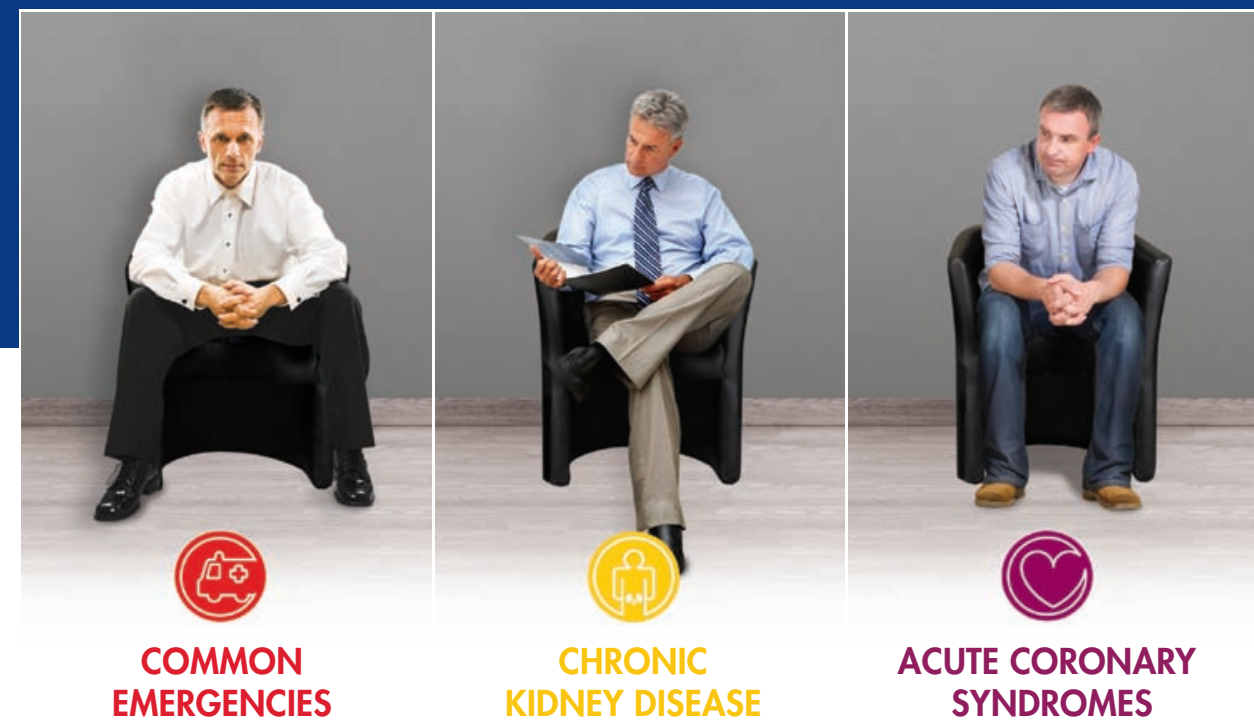

SYNDROMES
These courses were developed in collaboration with the CMA and Memorial University Professional Development and Conferencing Services through an educational grant from Pfizer Canada.
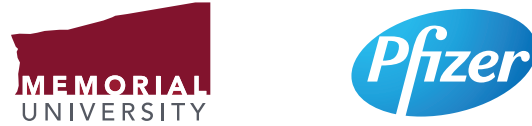

CANADIAN MEDICAL AsSOCIATION 